\title{
Modulation of adult-born neurons in the inflamed hippocampus
}

\author{
Karim Belarbi ${ }^{1,2}$ and Susanna Rosi ${ }^{1,2,3 *}$ \\ ${ }^{1}$ Brain and Spinal Injury Center, San Francisco General Hospital, University of California at San Francisco, San Francisco, CA, USA \\ ${ }^{2}$ Department of Physical Therapy and Rehabilitation Science, University of California at San Francisco, San Francisco, CA, USA \\ ${ }^{3}$ Department of Neurological Surgery, University of California at San Francisco, San Francisco, CA, USA
}

\author{
Edited by: \\ Marie-Eve Tremblay, Université Laval, \\ Canada

\section{Reviewed by:} \\ Valentin Nägerl, Institut \\ Interdisciplinaire de NeuroSciences, \\ Centre National de la Recherche \\ Scientifique, France \\ John A. Olschowka, University of \\ Rochester School of Medicine and \\ Dentistry, USA

\section{*Correspondence:} \\ Susanna Rosi, Brain and Spinal Injury \\ Center, San Francisco General \\ Hospital, University of California at \\ San Francisco, 1001 Potrero Avenue, \\ Building No. 1, Room No. 101, San \\ Francisco, CA 94110, USA \\ e-mail: rosis@ptrehab.ucsf.edu
}

Throughout life new neurons are continuously added to the hippocampal circuitry involved with spatial learning and memory. These new cells originate from neural precursors in the subgranular zone of the dentate gyrus, migrate into the granule cell layer, and integrate into neural networks encoding spatial and contextual information. This process can be influenced by several environmental and endogenous factors and is modified in different animal models of neurological disorders. Neuroinflammation, as defined by the presence of activated microglia, is a common key factor to the progression of neurological disorders. Analysis of the literature shows that microglial activation impacts not only the production, but also the migration and the recruitment of new neurons. The impact of microglia on adult-born neurons appears much more multifaceted than ever envisioned before, combining both supportive and detrimental effects that are dependent upon the activation phenotype and the factors being released. The development of strategies aimed to change microglia toward states that promote functional neurogenesis could therefore offer novel therapeutic opportunities against neurological disorders associated with cognitive deficits and neuroinflammation. The present review summarizes the current knowledge on how production, distribution, and recruitment of new neurons into behaviorally relevant neural networks are modified in the inflamed hippocampus.

Keywords: adult neurogenesis, chemokines, cytokines, inflammation, microglia

\section{INTRODUCTION}

In the adult mammalian brain, the subgranular zone of the dentate gyrus (DG) is one of the brain regions where robust neurogenesis continues throughout life (Altman and Das, 1965; Eriksson et al., 1998; Spalding et al., 2013). Adult-born neurons have the capacity to migrate into the granule cell layer, to differentiate into mature granule neurons and to functionally integrate into hippocampal neural networks. This process is highly plastic, influenced by environmental and endogenous factors, and it appears to be altered during neuropathological conditions (Parent et al., 1997; Dash et al., 2001; Ekdahl et al., 2003). In this review, we summarize the current knowledge on the plasticity of adult-born neurons in animal models of brain injury associated with neuroinflammation and we discuss the role of activated microglia and the contribution of specific inflammatory factors.

\section{FROM NEURAL PROGENITORS TO NEURONAL INTEGRATION INTO HIPPOCAMPAL NETWORKS}

Hippocampal adult-born neurons originate from neural precursor cells located in the subgranular zone of the DG and these cells have limited self-renewal capacity (Kempermann et al., 2003). While most of the newly generated cells die shortly after generation (Kempermann et al., 1997; Biebl et al., 2000), some of the progeny gives rise to neuroblasts that migrate into the DG granule cell layer where they mature into fully functional granule neurons (Kempermann et al., 2003; Esposito et al., 2005). The new cells that become synaptically integrated, receive inputs from the entorhinal cortex, and send axonal projections to hilar neurons and CA3 pyramidal cells (Markakis and Gage, 1999; Laplagne et al., 2007; Toni et al., 2008) can be activated by various stimuli, including behavioral experience (Jessberger and Kempermann, 2003; Ramirez-Amaya etal., 2006; Kee etal., 2007; Belarbi etal., 2012a) or high-frequency electrical perforant path stimulation (Bruel-Jungerman etal., 2006; Jungenitz et al., 2013). During their maturation process, new neurons differ substantially from existing granule cells. Electrophysiological data show that they exhibit a decreased overall induction threshold for long-term potentiation and enhanced synaptic plasticity compared to older neurons (Schmidt-Hieber et al., 2004; Ge et al., 2007). In response to spatial exploration, new neurons are also more likely to express plasticity-related immediate-early genes (IEGs) such as $\operatorname{Arc}$ (activity-regulated cytoskeleton-associated protein) or IEGs encoding transcription factors such as cfos (Ramirez-Amaya et al., 2006; Kee et al., 2007). Furthermore, numerous studies ablating or enhancing adult neurogenesis have demonstrated that hippocampal adult-born neurons are required for hippocampus-dependent forms of spatial memory (Clelland et al., 2009; Trouche et al., 2009; Goodman et al., 2010; Nakashiba et al., 2012). Collectively, these data indicate that adult-born neurons are more likely than existing granule neurons to be recruited into hippocampal networks that process spatial and contextual information and exert a critical role in hippocampus-dependent functions. 


\section{THE INFLAMED HIPPOCAMPUS AND THE MULTIFACETED ROLE OF MICROGLIA ACTIVATION}

Microglia derive from primitive myeloid progenitors and constitute the resident immune system in the brain (Ginhoux et al., 2010; Kierdorf et al., 2013). In the absence of pathological insult, microglia exist in a ramified morphological phenotype termed "resting microglia." Through their highly motile ramifications resting microglia continuously scan their territorial domain and communicate with the other surrounding cells by distinct signaling pathways (Davalos et al., 2005; Nimmerjahn et al., 2005; Hanisch and Kettenmann, 2007; Kettenmann et al., 2011). Furthermore, microglia transiently make contact with presynaptic boutons, postsynaptic spines, and the synaptic cleft (Wake et al., 2009; Tremblay et al., 2010) and facilitate synapses elimination and pruning, therefore likely contributing to the stability and organization of neural networks (Wake et al., 2009; Tremblay et al., 2010; Paolicelli et al., 2011). As a consequence of brain pathology, microglia respond to pathogen-associated or damage-associated molecules and acquire a reactive profile usually referred as "activated microglia." Typical morphological changes associated with microglia activation include thickening of ramifications and of cell bodies followed by acquisition of a rounded amoeboid shape (Kettenmann et al., 2011). This process is accompanied by expression of novel surface antigens and production of mediators that build up and maintain the inflammatory response of the brain parenchyma. This response is often associated with the recruitment of blood-born macrophages from the periphery which migrate into the injured brain parenchyma (Schilling et al., 2005; Schwartz and Shechter, 2010). Monocyte-derived macrophages are distinct in nature from resident microglia (for review, see London et al., 2013).

Activated microglia in the brain can operate as damage associated cells, producing a plethora of molecules that are essential for the elimination of pathogens, toxic factors (such as protein aggregates) and cellular debris (following neuronal death for example). By producing neurotrophic and growth factors that are pivotal for tissue repair and renewal they contribute to resolve infection or injury and to restore normal tissue homeostasis (Neumann et al., 2006; Lalancette-Hebert et al., 2007). On the other hand, through the release of proinflammatory cytokines, proteases, and reactive oxygen species they can induce neurotoxicity (Block et al., 2007; Hanisch and Kettenmann, 2007).

One of the brain regions most densely populated with microglia is the hippocampus (Lawson et al., 1990); microglia activation in this region is a common landmark following stimulation with the bacterial endotoxin lipopolysaccharide (LPS; Rosi et al., 2005; Belarbi etal., 2012a,b), ionizing irradiation (Monje et al., 2002, 2003; Rola etal., 2008; Rosi etal., 2008; Belarbi et al., 2013), traumatic brain injury (Piao et al., 2013), brain ischemia (Liu et al., 2007), and kainic acid-induced or pilocarpine-induced brain seizure (Andersson et al., 1991; Borges et al., 2003; Turrin and Rivest, 2004; Vezzani et al., 2008). Microglia activation is also present in various models of neurodegenerative diseases associated with abnormal protein aggregation such as in genetically modified mouse models mimicking Alzheimer's disease amyloid pathology (APP23: Stalder et al., 1999; Bornemann et al., 2001; PS/APP: Matsuoka et al., 2001; PS1 + APP: Gordon et al., 2002; Tg2576:
Frautschy et al., 1998; Benzing et al., 1999; Sasaki et al., 2002) or tau pathology (P301S tau: Bellucci et al., 2004; Yoshiyama et al., 2007; TgTauP301L: Sasaki et al., 2008; Thy-Tau22: Belarbi et al., 2011). Normal aging is also characterized by chronic low-level of inflammation and increased microglia reactivity (Jurgens and Johnson, 2012).

Both macrophages (Porta etal., 2009) and microglia (Michelucci et al., 2009) can undergo different forms of polarized activation leading to a potentially neurotoxic "classic or M1 activation" (characterized by a release of pro-inflammatory factors) or a potentially neuroprotective "alternative or M2 activation" (characterized by anti-inflammatory cytokines). M1 activation is characterized by the release of several proinflammatory and neurotoxic factors including reactive oxygen species, nitric oxide, TNF-alpha, Il-6, Il-1beta, Il-12, and monocyte chemoattractant protein (MCP)-1 (Meda etal., 1996; Kettenmann etal., 2011; Qin et al., 2013). Polarization toward classic activation (M1) can be induced experimentally by exposure to pro-inflammatory cytokines such as interferon (IFN)-gamma, tumor necrosis factor (TNF)-alpha and interleukin (Il)-1beta, as well as bacterial-derived LPS (Lehnardt et al., 2003). Alternative M2 (protective) activation of microglia is characterized by increased expression of the anti-inflammatory cytokines Il4, Il-10, and transforming growth factor (TGF)-beta, CD200, and growth factors such as insulin growth factor (IGF)-1, nerve growth factor (NGF) or brain-derived neurotrophic factor (BDNF; Butovsky et al., 2005; Yi et al., 2012). Alternative activation can be induced experimentally by anti-inflammatory cytokines such as Il-4 and Il-13 (Butovsky etal., 2006; Colton, 2009). The regulation of this functional polarization after brain injury is still not clear and evidence shows that it should be considered as a dynamic process (Colton, 2009). For example, following ischemia-induced injury in the striatum, microglia initially express the classic activation phenotype, but with time a portion of the cells acquire the alternative activation phenotype (Thored etal., 2009). Therefore, the link between activated microglia and neurogenesis is multifaceted, combining both supportive and detrimental effects dependent upon their phenotype and the factors being released (Butovsky et al., 2006; Figure 1).

\section{PRODUCTION OF NEURONS IN THE INFLAMED HIPPOCAMPUS}

Proliferation, differentiation, and survival of neurons in the adult brain has been shown to be modulated in pathological conditions associated with inflammation (Cho and Kim, 2010; Mu and Gage, 2011; Kohman and Rhodes, 2013). Animal models of brain irradiation typically display a significant loss of neural precursor cells that occurs within a few hours (Mizumatsu et al., 2003) and is still present several months after relatively low radiation doses (Tada et al., 2000; Raber et al., 2004a,b; Belarbi et al., 2013). Similarly, neuroinflammation induced by central or systemic administration of LPS significantly reduces basal neurogenesis (Ekdahl et al., 2003; Monje et al., 2003; Fujioka and Akema, 2010), although this is not observed when very low doses of LPS are chronically infused in the ventricular system (Belarbi et al., 2012a). In contrast, increased neuronal production has been 


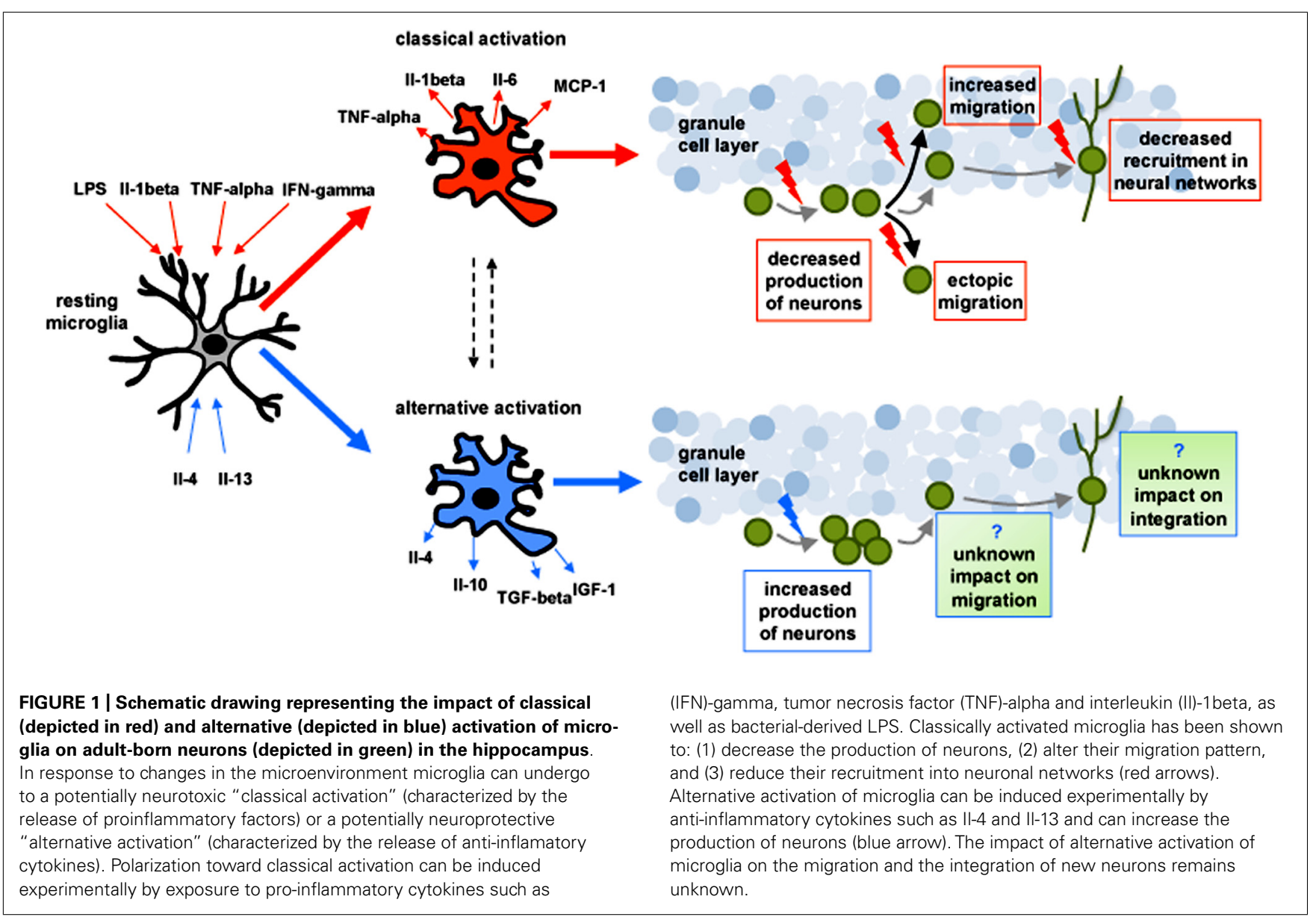

reported in animal models of experimental traumatic brain injury (Dash et al., 2001; Kernie et al., 2001; Chirumamilla et al., 2002; Emery etal., 2005; Sun etal., 2007), brain ischemia (Liu et al., 1998; Kee et al., 2001; Yagita et al., 2001; Nakatomi et al., 2002; Choi et al., 2003), and kainic acid-induced or pilocarpine-induced status epilepticus (Parent et al., 1997; Choi et al., 2007). Different animal models of Alzheimer's disease, provided equivocal data, demonstrating both increased and decreased hippocampal neurogenesis (as reviewed in $\mathrm{Mu}$ and Gage, 2011). While differences in many parameters (bromodeoxyuridine administration, cell markers, etc.) could be the cause for these discrepancies, such data provide strong evidence that the modulation of hippocampal adult-born neurons is dependent on the nature of the injury and the time following injury. The initial work investigating the role of activated microglia on neurogenesis found an acute detrimental role for these cells. Classic activation of microglia induced through administration of LPS, either centrally or peripherally, has been shown to block hippocampal neurogenesis (Ekdahl et al., 2003; Monje et al., 2003; Butovsky etal., 2006). In addition, inhibition of microglial activation through administration of minocycline or indomethacin was shown to rescue hippocampal neurogenesis after LPS-induced inflammation (Monje et al., 2003), cranial irradiation (Ekdahl et al., 2003), or focal cerebral ischemia (Hoehn etal., 2005; Liu etal., 2007). In contrast, alternative microglia activation through Il-4 or low level of IFN-gamma could promote neurogenesis (Butovsky et al., 2006). Proinflammatory cytokines released by classically activated microglia can specifically inhibit neural precursor generation, neuronal differentiation, and survival. These include TNF-alpha (Cacci et al., 2005; Heldmann et al., 2005; Iosif et al., 2006), Il-1beta (Goshen et al., 2008; Koo and Duman, 2008; Kuzumaki et al., 2010; Wu et al., 2012), and Il-6 (Vallieres et al., 2002). Conversely, factors released by alternative activation of microglia seem to support the production of neurons as shown for Il-4 (Kiyota et al., 2010), Il-10 (Kiyota et al., 2012), TGF-beta (Battista et al., 2006; Mathieu et al., 2010), and IGF-1 (Choi et al., 2008; Annenkov, 2009). Taken together, these findings suggest that classically activated microglia generally impair neurogenesis whereas alternatively activated microglia promote it, and that these opposite effects are likely dependent upon the specific factors being released (Figure 1).

\section{DISTRIBUTION OF ADULT-BORN NEURONS IN THE INFLAMED HIPPOCAMPUS}

In the normal hippocampus neuronal precursors migrate a few micrometers into the granule cell layer where they differentiate into new neurons during the first 2 weeks after production (Kempermann et al., 2003; Seki et al., 2007; Sandoval et al., 2011; Belarbi et al., 2013). Comparative analyses of the distribution of adultborn neurons in different animal models of brain injury suggest 
that the migration process is altered during pathological conditions. Parent and colleagues first reported ectopic destinations of neural progenitor cells after pilocarpine-induced seizure. Mature neurons were detected not only inside the granule cell layer but also in the molecular layer and inside the hilus of the DG (Parent et al., 1997, 2006). Altered distribution of new neurons within the hippocampus has been also reported in murine models of stroke (Kernie and Parent, 2010), traumatic brain injury (Rosi et al., 2012), cranial-irradiation (Belarbi et al., 2013), and LPSinduced chronic inflammation (Belarbi et al., 2012a). In these models, new neurons were distributed in average a longer distance from the subgranular zone into the granule cell layer. Additional evidence for modified migration of new neurons in the inflamed hippocampus comes from the work of Belmadani et al. (2006) who demonstrated that small cytokine signaling proteins, named chemokines, regulate the migration of neural progenitors to sites of neuroinflammation. In that study neural progenitor cells were grafted into the DG of cultured hippocampal slices and inflammation was achieved by injecting a solution, containing TNF-alpha, IFN-gamma, LPS, glycoprotein 120, or a beta-amyloid-expressing adenovirus, into the area of the fimbria. In control slices, neural progenitors showed little tendency to migrate, while in slices injected with inflammatory stimuli, neural progenitors migrated toward the site of the injection. However, when neural precursors from mice lacking the $\mathrm{C}-\mathrm{C}$ chemokine receptor type 2 (CCR2 knock-out) were transplanted into slices, they exhibited a greatly reduced migration toward sites of inflammation (Belmadani et al., 2006). CCR2 and its primary ligand MCP-1 are considered to be critical for macrophage trafficking and activation in the brain (Prinz and Priller, 2010). CCR2 has also been shown to be expressed by neural progenitors (Tran et al., 2007). Therefore, these data further support a role for chemokines in the migration of neural progenitor during inflammation. In line with these findings, we recently reported that CCR2 deficiency, through genetic manipulation in mice, was sufficient to prevent the aberrant migration of new neurons observed in vivo following irradiation (Belarbi et al., 2013). Similarly, in the pilocarpine-induced status epilepticus rat model, the blockade of the MCP-1/CCR2 interaction with a selective CCR2 antagonist attenuated the ectopic migration of neuronal progenitors into the hilus (Hung et al., 2013). Collectively, these findings indicate that adult-born neurons have the capacity to migrate to the site of damage in response to the chemokine MCP-1/CCR2 signaling pathway. Currently, it is not known whether the change in migration induced by inflammation is beneficial, as, for example, increased migration would allow new neurons to replace dying or lost neurons, or deleterious, as altered migration could reflect the formation of aberrant circuits disrupting hippocampal functions.

\section{RECRUITMENT OF ADULT-BORN NEURONS INTO BEHAVIORALLY RELEVANT NEURAL NETWORKS IN THE INFLAMED HIPPOCAMPUS}

It is widely accepted that induction of effective synaptic plasticity associated with learning and memory requires de novo protein synthesis (Miyashita etal., 2008). The IEG Arc and its protein are dynamically regulated in response to neuronal activity, and are directly involved in plasticity processes that underlie memory consolidation (Guzowski et al., 2000). The expression of behaviorally induced Arc can be used to study the recruitment of adult-born mature neurons into functional neural networks. Using plasticity-related Arc expression, Ramirez-Amaya and coworkers demonstrated that the proportion of mature new neurons that expressed Arc in response to exploration was significantly higher than the proportion of cells that expressed Arc in the already existing population of granule cells. These data indicate that new neurons are preferentially recruited into hippocampal networks encoding spatial and contextual information (Ramirez-Amaya etal., 2006). In a rat model of LPS-induced chronic neuroinflammation 2-month-old neurons retained the capacity to express behaviorally induced Arc in response to spatial exploration. However, the proportion of new neurons that expressed behaviorally induced Arc was significantly lower than that from sham control animals, indicating that chronic inflammation decreased the recruitment of new neurons into hippocampal networks (Belarbi et al., 2012a). These findings are consistent with the work of Jakubs et al. (2008) that reported an increased inhibitory synaptic drive of new neurons that developed during LPS-induced neuroinflammation. Although adult-born neurons likely contribute to the encoding of recent spatial and contextual information, it is difficult to determine whether decreased excitability of new neurons is beneficial or deleterious to brain function during inflammatory conditions. Indeed, because neuroinflammation was shown to increase the proportion of granule cells expressing behaviorally induced Arc (Rosi et al., 2005), the decrease in new neurons expressing behaviorally induced Arc may be a compensatory mechanism to maintain an optimal level of neuronal activation and ensure the maintenance of pattern separation using a very sparse coding strategy (McNaughton et al., 1996; Rosi, 2011). Arc expression in new neurons as response to behavioral exploration was also reported in mice following exposure to low-dose irradiation combined or not with a subsequent traumatic brain injury in the presence of activated microglia (Rosi et al., 2012). Collectively, these findings show that while new neurons retain the capacity to be recruited into behaviorally relevant neural networks following brain injury, their recruitment is significantly decreased following classical microglia activation.

The chemokine receptor CX3CR1 is present in microglia and circulating monocytes and its unique ligand fractalkine (CX3CL1) is expressed in neurons and peripheral endothelia cells (Bazan etal., 1997; Mizoue etal., 1999). CX3CL1 signaling in the brain promotes microglial survival and controls microglial neurotoxicity through its receptor CX3CR1 under certain neurodegenerative and inflammatory conditions (Garcia et al., 2013). CX3CL1/CX3CR1 signaling is regulated in the inflamed brain, and CX3CR1 is a key regulator of microglia activation contributing to adaptive immune responses (Garcia et al., 2013). Recent evidence demonstrates that in the uninjured brain microglia play a critical role in monitoring and maintaining synapses by directly interacting with synaptic elements (Wake etal., 2009; Tremblay et al., 2010; Paolicelli et al., 2011). Using CX3CR1 knockout mice, Paolicelli et al. (2011) reported a transient reduction in microglial numbers paralleled by a delay in synaptic pruning with consequent excess of dendritic spines and a delayed maturation of 
excitatory transmission in the developing brain. These results, together with recent data (Rogers et al., 2011; Hoshiko et al., 2012) suggest that CX3CL1/CX3CR1 is an important neuron-microglia signaling pathway necessary for synaptic pruning and maturation (Paolicelli et al., 2011). In light of the role of CX3CL1/CX3CR1 signaling in synaptic maturation together with its involvement in inflammation, it is possible that in the inflamed hippocampus the alteration of this signaling pathway may lead to delayed maturation and/or integration of adult-born neurons. Further studies are needed to better understand how microglia may impact the maturation of adult-born neurons depending of their activation phenotype and the different signaling molecules.

\section{PERSPECTIVES AND CONCLUDING REMARKS}

Available data indicate that the generation, migration, and functional integration of adult-born neurons can be modulated in the inflamed hippocampus, and this modulation appears to differ depending on the activation phenotype of microglia and the specific factors that they release. It is now clear that the range of impact of microglia on adult-born neurons is wider than previously thought, as demonstrated by the anti-neurogenic and pro-neurogenic effects of opposite pro-inflammatory and anti-inflammatory polarized microglia. Previous strategies aimed

\section{REFERENCES}

Altman, J., and Das, G. D. (1965). Autoradiographic and histological evidence of postnatal hippocampal neurogenesis in rats. J. Comp. Neurol. 124, 319-335. doi: 10.1002/cne.901240303

Andersson, P. B., Perry, V. H., and Gordon, S. (1991). The kinetics and morphological characteristics of the macrophage-microglial response to kainic acid-induced neuronal degeneration. Neuroscience 42, 201-214. doi: 10.1016/0306-4522(91)90159-L

Annenkov, A. (2009). The insulin-like growth factor (IGF) receptor type 1 (IGF1R) as an essential component of the signalling network regulating neurogenesis. Mol. Neurobiol. 40, 195-215. doi: 10.1007/s12035-0098081-0

Battista, D., Ferrari, C. C., Gage, F. H., and Pitossi, F. J. (2006). Neurogenic niche modulation by activated microglia: transforming growth factor beta increases neurogenesis in the adult dentate gyrus. Eur. J. Neurosci. 23, 83-93. doi: 10.1111/j.14609568.2005.04539.x

Bazan, J. F., Bacon, K. B., Hardiman, G., Wang, W., Soo, K., Rossi, D., et al. (1997). A new class of membrane-bound chemokine with a CX3C motif. Nature 385, 640-644. doi: 10.1038/385640a0

Belarbi, K., Arellano, C., Ferguson, R., Jopson, T., and Rosi, S. (2012a). Chronic neuroinflammation impacts neurons into behaviorally relevant hippocampal networks. Brain Behav. Immun. 26, 18-23. doi: 10.1016/j.bbi. 2011.07.225

Belarbi, K., Jopson, T., Tweedie, D., Arellano, C., Luo, W., Greig, N. H., et al. (2012b). TNF-alpha protein synthesis inhibitor restores neuronal function and reverses cognitive deficits induced by chronic neuroinflammation. J. Neuroinflammation 9, 23. doi: 10.1186/17422094-9-23

Belarbi, K., Burnouf, S., FernandezGomez, F. J., Laurent, C., Lestavel S., Figeac, M., et al. (2011). Beneficial effects of exercise in a transgenic mouse model of Alzheimer's diseaselike Tau pathology. Neurobiol. Dis. 43, 486-494. doi: 10.1016/j.nbd. 2011.04 .022

Belarbi, K., Jopson, T., Arellano, C., Fike, J. R., and Rosi, S. (2013). CCR2 deficiency prevents neuronal dysfunction and cognitive impairments induced by cranial irradiation. Cancer Res. 73, 1201-1210. doi: 10.1158/00085472.CAN-12-2989

Bellucci, A., Westwood, A. J., Ingram, E., Casamenti, F., Goedert, M., and Spillantini, M. G. (2004). Induction of inflammatory mediators and microglial activation in mice transgenic for mutant human P301S tau protein. Am. J. Pathol. 165, 1643-1652. doi: 10.1016/S00029440(10)63421-9 the recruitment of adult-born

to maintain functional neurogenesis have mainly focused on decreasing microglia activation. While recent data highlight the potential neuroprotective role of microglia following brain injury, it appears that transforming their phenotype toward alternative activation states could optimize the production, migration, and integration of neurons. Future studies are needed to: (i) characterize the phenotype of microglia activation and the microglia-released factors following brain injury, taking into account the nature of the injury and the timing following the injury; (ii) understand how specific microglia activation states and microglia-released factors impact functional neurogenesis, including migration and functional integration; (iii) identify ways to induce activation of microglia that would support functional neurogenesis in the injured brain. These steps are of critical importance to develop immune-mediated strategies to promote efficient adult-born neurons integration for the maintenance or improvement of hippocampus-dependent cognitive function.

\section{ACKNOWLEDGMENTS}

We would like to thank Professor John R. Fike for the editorial help with this manuscript. This work was supported by the NIH R01 CA133216 (Susanna Rosi) and the Alzheimer's Association IIRG-11-202064 (Susanna Rosi).

Belmadani, A., Tran, P. B., Ren, D., and Miller, R. J. (2006). Chemokines regulate the migration of neural progenitors to sites of neuroinflammation. J. Neurosci. 26, 3182-3191. doi: 10.1523/JNEUROSCI.015606.2006

Benzing, W. C., Wujek, J. R., Ward, E. K., Shaffer, D., Ashe, K. H., Younkin, S. G., etal. (1999). Evidence for glial-mediated inflammation in aged $\mathrm{APP}(\mathrm{SW})$ transgenic mice. Neurobiol. Aging 20, 581589. doi: 10.1016/S0197-4580(99) 00065-2

Biebl, M., Cooper, C. M., Winkler, J., and Kuhn, H. G. (2000). Analysis of neurogenesis and programmed cell death reveals a self-renewing capacity in the adult rat brain. Neurosci. Lett. 291, 17-20. doi: 10.1016/S03043940(00)01368-9

Block, M. L., Zecca, L., and Hong, J. S. (2007). Microgliamediated neurotoxicity: uncovering the molecular mechanisms. Nat. Rev. Neurosci. 8, 57-69. doi: 10.1038/ nrn2038

Borges, K., Gearing, M., Mcdermott, D. L., Smith, A. B., Almonte, A. G. Wainer, B. H., et al. (2003). Neuronal and glial pathological changes during epileptogenesis in the mouse pilocarpine model. Exp. Neurol. 182, 21-34. doi: 10.1016/S00144886(03)00086-4

Bornemann, K. D., Wiederhold, K. H., Pauli, C., Ermini, F., Stalder
M., Schnell, L., et al. (2001). Abetainduced inflammatory processes in microglia cells of APP23 transgenic mice. Am. J. Pathol. 158, 6373. doi: 10.1016/S0002-9440(10) 63945-4

Bruel-Jungerman, E., Davis, S., Rampon, C., and Laroche, S. (2006). Long-term potentiation enhances neurogenesis in the adult dentate gyrus. J. Neurosci. 26, 5888-5893. doi: 10.1523/JNEUROSCI.0782-0 6.2006

Butovsky, O., Talpalar, A. E., BenYaakov, K., and Schwartz, M. (2005). Activation of microglia by aggregated beta-amyloid or lipopolysaccharide impairs MHC-II expression and renders them cytotoxic whereas IFN-gamma and IL-4 render them protective. Mol. Cell. Neurosci. 29, 381-393. doi: 10.1016/j.mcn.2005. 03.005

Butovsky, O., Ziv, Y., Schwartz, A., Landa, G., Talpalar, A. E., Pluchino, S., et al. (2006). Microglia activated by IL- 4 or IFN-gamma differentially induce neurogenesis and oligodendrogenesis from adult stem/progenitor cells. Mol. Cell. Neurosci. 31, 149-160. doi: 10.1016/j.mcn.2005. 10.006

Cacci, E., Claasen, J. H., and Kokaia, Z. (2005). Microglia-derived tumor necrosis factor-alpha exaggerates death of newborn hippocampal progenitor cells in vitro. J. 
Neurosci. Res. 80, 789-797. doi: 10.1002/jnr.20531

Chirumamilla, S., Sun, D., Bullock, M. R., and Colello, R. J. (2002). Traumatic brain injury induced cell proliferation in the adult mammalian central nervous system. J. Neurotrauma 19, 693 703. doi: 10.1089/089771502601 39084

Cho, K. O., and Kim, S. Y. (2010). Effects of brain insults and pharmacological manipulations on the adult hippocampal neurogenesis. Arch. Pharm. Res. 33, 1475-1488. doi: 10.1007/s12272-010-1002-y

Choi, Y. S., Cho, H. Y., Hoyt, K. R., Naegele, J. R., and Obrietan, K. (2008). IGF-1 receptor-mediated ERK/MAPK signaling couples status epilepticus to progenitor cell proliferation in the subgranular layer of the dentate gyrus. Glia 56, 791-800. doi: 10.1002/glia.20653

Choi, Y. S., Cho, K. O., and Kim, S. Y. (2007). Asymmetry in enhanced neurogenesis in the rostral dentate gyrus following kainic acid-induced status epilepticus in adult rats. Arch. Pharm. Res. 30, 646-652. doi: 10.1007/BF02977661

Choi, Y. S., Lee, M. Y., Sung, K. W., Jeong, S. W., Choi, J. S., Park, H. J., et al. (2003). Regional differences in enhanced neurogenesis in the dentate gyrus of adult rats after transient forebrain ischemia. Mol. Cells 16, 232-238.

Clelland, C. D., Choi, M., Romberg, C., Clemenson, G. D. Jr., Fragniere, A., Tyers, P., et al. (2009). A functional role for adult hippocampal neurogenesis in spatial pattern separation. Science 325, 210-213. doi: 10.1126/science. 1173215

Colton, C. A. (2009). Heterogeneity of microglial activation in the innate immune response in the brain. J. Neuroimmune Pharmacol. 4 399-418. doi: 10.1007/s11481-0099164-4

Dash, P. K., Mach, S. A., and Moore, A. N. (2001). Enhanced neurogenesis in the rodent hippocampus following traumatic brain injury. J. Neurosci. Res. 63, 313-319. doi: 10.1002/10974547(20010215)63:4<313::AIDJNR1025>3.0.CO;2-4

Davalos, D., Grutzendler, J., Yang, G., Kim, J. V., Zuo, Y., Jung, S., etal. (2005). ATP mediates rapid microglial response to local brain injury in vivo. Nat. Neurosci. 8, 752-758. doi: 10.1038/nn1472

Ekdahl, C. T., Claasen, J. H., Bonde, S., Kokaia, Z., and Lindvall, O. (2003). Inflammation is detrimental for neurogenesis in adult brain. Proc.
Natl. Acad. Sci. U.S.A. 100, 13632 13637. doi: 10.1073/pnas.22340 31100

Emery, D. L., Fulp, C. T., Saatman, K. E., Schutz, C., Neugebauer, E., and Mcintosh, T. K. (2005). Newly born granule cells in the dentate gyrus rapidly extend axons into the hippocampal CA3 region following experimental brain injury. J. Neurotrauma 22, 978-988. doi: 10.1089/neu.2005.22.978

Eriksson, P. S., Perfilieva, E., BjorkEriksson, T., Alborn, A. M. Nordborg, C., Peterson, D. A., et al. (1998). Neurogenesis in the adult human hippocampus. Nat. Med. 4, 1313-1317. doi: 10.1038/ 3305

Esposito, M. S., Piatti, V. C., Laplagne, D. A., Morgenstern, N. A., Ferrari, C. C., Pitossi, F. J., et al. (2005). Neuronal differentiation in the adult hippocampus recapitulates embryonic development. J. Neurosci. 25, 10074-10086. doi: 10.1523 JNEUROSCI.3114-05.2005

Frautschy, S. A., Yang, F., Irrizarry, M., Hyman, B., Saido, T. C., Hsiao, K., et al. (1998). Microglial response to amyloid plaques in APPsw transgenic mice. Am. J. Pathol. 152, 307-317.

Fujioka, H., and Akema, T. (2010). Lipopolysaccharide acutely inhibits proliferation of neural precursor cells in the dentate gyrus in adult rats. Brain Res. 1352, 3542. doi: 10.1016/j.brainres.2010. 07.032

Garcia, J. A., Pino, P. A., Mizutani, M., Cardona, S. M., Charo, I. F., Ransohoff, R. M., et al. (2013). Regulation of adaptive immunity by the fractalkine receptor during autoimmune inflammation. J. Immunol. 19, 1063-1072. doi: 10.4049/jimmunol.1300040

Ge, S., Yang, C. H., Hsu, K. S., Ming, G. L., and Song, H. (2007). A critical period for enhanced synaptic plasticity in newly generated neurons of the adult brain. Neuron 54 559-566. doi: 10.1016/j.neuron.2007. 05.002

Ginhoux, F., Greter, M., Leboeuf, M., Nandi, S., See, P., Gokhan, S. etal. (2010). Fate mapping analysis reveals that adult microglia derive from primitive macrophages. Science 330, 841-845. doi: 10.1126/science. 1194637

Goodman, T., Trouche, S., Massou, I., Verret, L., Zerwas, M., Roullet, P., et al. (2010). Young hippocampal neurons are critical for recent and remote spatial memory in adult mice. Neuroscience 171, 769-778. doi: $\quad$ 10.1016/j.neuroscience.2010 09.047

Gordon, M. N., Holcomb, L. A., Jantzen, P. T., Dicarlo, G., Wilcock, D., Boyett, K. W., et al. (2002). Time course of the development of Alzheimer-like pathology in the doubly transgenic PS1 + APP mouse. Exp. Neurol. 173, 183-195. doi: 10.1006/exnr.2001.7754

Goshen, I., Kreisel, T., Ben-MenachemZidon, O., Licht, T., Weidenfeld, J., Ben-Hur, T., et al. (2008). Brain interleukin-1 mediates chronic stress-induced depression in mice via adrenocortical activation and hippocampal neurogenesis suppression. Mol. Psychiatry 13, 717-728. doi: 10.1038/sj.mp.4002055

Guzowski, J. F., Lyford, G. L., Stevenson, G. D., Houston, F. P., Mcgaugh, J. L., Worley, P. F., etal. (2000). Inhibition of activity-dependent arc protein expression in the rat hippocampus impairs the maintenance of long-term potentiation and the consolidation of long-term memory. J. Neurosci. 20, 3993-4001.

Hanisch, U. K., and Kettenmann, H. (2007). Microglia: active sensor and versatile effector cells in the normal and pathologic brain. Nat. Neurosci. 10, 1387-1394. doi: 10.1038/ nn1997

Heldmann, U., Thored, P., Claasen, J. H., Arvidsson, A., Kokaia, Z., and Lindvall, O. (2005). TNF-alpha antibody infusion impairs survival of stroke-generated neuroblasts in adult rat brain. Exp. Neurol. 196, 204 208. doi: 10.1016/j.expneurol.2005 07.024

Hoehn, B. D., Palmer, T. D., and Steinberg, G. K. (2005). Neurogenesis in rats after focal cerebral ischemia is enhanced by indomethacin. Stroke 36, 2718-2724. doi: 10.1161/01.STR.0000190020. 30282.cc

Hoshiko, M., Arnoux, I., Avignone, E., Yamamoto, N., and Audinat, E. (2012). Deficiency of the microglial receptor CX3CR1 impairs postnatal functional development of thalamocortical synapses in the barrel cortex. J. Neurosci. 32, 15106-15111. doi: 10.1523/JNEUROSCI.1167 12.2012

Hung, Y. W., Lai, M. T., Tseng, Y. J., Chou, C. C., and Lin, Y. Y. (2013). Monocyte chemoattractant protein1 affects migration of hippocampal neural progenitors following status epilepticus in rats. J. Neuroinflammation 10, 11. doi: 10.1186/1742-209410-11

Iosif, R. E., Ekdahl, C. T., Ahlenius, H., Pronk, C. J., Bonde, S., Kokaia,
Z., et al. (2006). Tumor necrosis factor receptor 1 is a negative regulator of progenitor proliferation in adult hippocampal neurogenesis. J. Neurosci. 26, 9703-9712. doi: 10.1523/JNEUROSCI.2723 06.2006

Jakubs, K., Bonde, S., Iosif, R. E., Ekdahl, C. T., Kokaia, Z., Kokaia, M., etal. (2008). Inflammation regulates functional integration of neurons born in adult brain. J. Neurosci. 28, 12477-12488. doi: 10.1523/JNEUROSCI.3240-08. 2008

Jessberger, S., and Kempermann, G. (2003). Adult-born hippocampal neurons mature into activitydependent responsiveness. Eur. J. Neurosci. 18, 2707-2712. doi: 10.1111/j.1460-9568.2003.02986.x

Jungenitz, T., Radic, T., Jedlicka, P., and Schwarzacher, S. W. (2013). High-frequency stimulation induces gradual immediate early gene expression in maturing adult-generated hippocampal granule cells. Cereb. Cortex. doi: 10.1093/cercor/bht035 [Epub ahead of print].

Jurgens, H. A., and Johnson, R. W. (2012). Dysregulated neuronalmicroglial cross-talk during aging, stress and inflammation. Exp. Neurol. 233, 40-48. doi: 10.1016/j. expneurol.2010.11.014

Kee, N., Teixeira, C. M., Wang, A. H., and Frankland, P. W. (2007). Preferential incorporation of adultgenerated granule cells into spatial memory networks in the dentate gyrus. Nat. Neurosci. 10, 355-362. doi: $10.1038 / \mathrm{nn} 1847$

Kee, N. J., Preston, E., and Wojtowicz, J. M. (2001). Enhanced neurogenesis after transient global ischemia in the dentate gyrus of the rat. Exp. Brain Res. 136, 313-320. doi: 10.1007/s002210000591

Kempermann, G., Gast, D., Kronenberg, G., Yamaguchi, M., and Gage, F. H. (2003). Early determination and long-term persistence of adult-generated new neurons in the hippocampus of mice. Development 130, 391-399. doi: 10.1242/dev. 00203

Kempermann, G., Kuhn, H. G., and Gage, F. H. (1997). Genetic influence on neurogenesis in the dentate gyrus of adult mice. Proc. Natl. Acad. Sci. U.S.A. 94, 10409-10414. doi: 10.1073/pnas.94.19.10409

Kernie, S. G., Erwin, T. M., and Parada, L. F. (2001). Brain remodeling due to neuronal and astrocytic proliferation after controlled cortical injury in mice. J. Neurosci. Res. 66, 317-326. doi: 10.1002/jnr.10013 
Kernie, S. G., and Parent, J. M. (2010). Forebrain neurogenesis after focal Ischemic and traumatic brain injury. Neurobiol. Dis. 37, 267-274. doi: 10.1016/j.nbd.2009.11.002

Kettenmann, H., Hanisch, U. K., Noda, M., and Verkhratsky, A. (2011). Physiology of microglia. Physiol. Rev. 91, 461-553. doi: 10.1152/physrev.00011.2010

Kierdorf, K., Erny, D., Goldmann, T., Sander, V., Schulz, C., Perdiguero, E. G., et al. (2013). Microglia emerge from erythromyeloid precursors via Pu.1- and Irf8-dependent pathways. Nat. Neurosci. 16, 273-280. doi: 10.1038/nn.3318

Kiyota, T., Ingraham, K. L., Swan, R. J., Jacobsen, M. T., Andrews, S. J., and Ikezu, T. (2012). AAV serotype 2/1-mediated gene delivery of anti-inflammatory interleukin-10 enhances neurogenesis and cognitive function in APP + PS1 mice Gene Ther. 19, 724-733. doi: 10.1038/gt.2011.126

Kiyota, T., Okuyama, S., Swan, R. J., Jacobsen, M. T., Gendelman, H. E., and Ikezu, T. (2010). CNS expression of antiinflammatory cytokine interleukin4 attenuates Alzheimer's disease-like pathogenesis in APP + PS1 bigenic mice. FASEB J. 24, 3093-3102. doi 10.1096/fj.10-155317

Kohman, R. A., and Rhodes, J. S. (2013). Neurogenesis, inflammation and behavior. Brain Behav. Immun. 27, 22-32. doi: 10.1016/j.bbi. 2012.09.003

Koo, J. W., and Duman, R. S. (2008) IL-1beta is an essential mediator of the antineurogenic and anhedonic effects of stress. Proc. Natl. Acad. Sci. U.S.A. 105, 751-756. doi: 10.1073/pnas.0708092105

Kuzumaki, N., Ikegami, D., Imai, S., Narita, M., Tamura, R., Yajima, M. et al. (2010). Enhanced IL-1beta production in response to the activation of hippocampal glial cells impairs neurogenesis in aged mice. Synapse 64, 721-728. doi: 10.1002/syn. 20800

Lalancette-Hebert, M., Gowing, G., Simard, A., Weng, Y. C., and Kriz, J. (2007). Selective ablation of proliferating microglial cells exacerbates ischemic injury in the brain. J. Neurosci. 27, 2596-2605.

Laplagne, D. A., Kamienkowski, J. E., Esposito, M. S., Piatti, V. C., Zhao, C., Gage, F. H., et al. (2007). Similar GABAergic inputs in dentate granule cells born during embryonic and adult neurogenesis. Eur. J. Neurosci. 25, 2973-2981. doi: 10.1111/j.14609568.2007.05549.x
Lawson, L. J., Perry, V. H., Dri, P., and Gordon, S. (1990). Heterogeneity in the distribution and morphology of microglia in the normal adult mouse brain. Neuroscience 39, 151170. doi: $10.1016 / 0306-4522(90)$ 90229-W

Lehnardt, S., Massillon, L., Follett, P. Jensen, F. E., Ratan, R., Rosenberg, P. A., et al. (2003). Activation of innate immunity in the CNS triggers neurodegeneration through a Toll-like receptor 4-dependent pathway. Proc. Natl. Acad. Sci. U.S.A. 100, 8514 8519. doi: 10.1073/pnas. 1432609100

Liu, J., Solway, K., Messing, R. O., and Sharp, F. R. (1998). Increased neurogenesis in the dentate gyrus after transient global ischemia in gerbils. $J$. Neurosci. 18, 7768-7778.

Liu, Z., Fan, Y., Won, S. J., Neumann, M., Hu, D., Zhou, L., et al. (2007). Chronic treatment with minocycline preserves adult new neurons and reduces functional impairment after focal cerebral ischemia. Stroke 38, 146-152. doi: 10.1161/ 01.STR.0000251791.64910.cd

London, A., Cohen, M., and Schwartz, M. (2013). Microglia and monocytederived macrophages: functionally distinct populations that act in concert in CNS plasticity and repair. Front. Cell. Neurosci. 7:34. doi: 10.3389/fncel.2013.00034

Markakis, E. A., and Gage, F. H. (1999). Adult-generated neurons in the dentate gyrus send axonal projections to field $\mathrm{CA} 3$ and are surrounded by synaptic vesicles. J. Comp. Neurol. 406, 449-460. doi: 10.1002/(SICI)10969861(19990419)406:4<449::AID-

CNE3 >3.0.CO;2-I

Mathieu, P., Piantanida, A. P., and Pitossi, F. (2010). Chronic expression of transforming growth factor-beta enhances adult neurogenesis. $\mathrm{Neu}$ roimmunomodulation 17, 200-201. doi: $10.1159 / 000258723$

Matsuoka, Y., Picciano, M., Malester, B., Lafrancois, J., Zehr, C. Daeschner, J. M., etal. (2001). Inflammatory responses to amyloidosis in a transgenic mouse mode of Alzheimer's disease. Am. J. Pathol. 158, 1345-1354. doi: 10.1016/S0002 9440(10)64085-0

McNaughton, B. L., Barnes, C. A., Gerrard, J. L., Gothard, K., Jung, M. W., Knierim, J. J., et al. (1996). Deciphering the hippocampal polyglot: the hippocampus as a path integration system. J. Exp. Biol. 199, 173-185.

Meda, L., Bernasconi, S., Bonaiuto, C. Sozzani, S., Zhou, D., Otvos, L. Jr., et al. (1996). Beta-amyloid (25-35) peptide and IFN-gamma synergistically induce the production of the chemotactic cytokine MCP-1/JE in monocytes and microglial cells. $J$. Immunol. 157, 1213-1218.

Michelucci, A., Heurtaux, T., Grandbarbe, L., Morga, E., and Heuschling, P. (2009). Characterization of the microglial phenotype under specific pro-inflammatory and antiinflammatory conditions: Effects of oligomeric and fibrillar amyloidbeta. J. Neuroimmunol. 210, $3-$ 12. doi: 10.1016/j.jneuroim.2009. 02.003

Miyashita, T., Kubik, S., Lewandowski, G., and Guzowski, J. F. (2008) Networks of neurons, networks of genes: an integrated view of memory consolidation. Neurobiol. Learn. Mem. 89, 269-284. doi: 10.1016/ j.nlm.2007.08.012

Mizoue, L. S., Bazan, J. F., Johnson, E. C., and Handel, T. M. (1999). Solution structure and dynamics of the $\mathrm{CX} 3 \mathrm{C}$ chemokine domain of fractalkine and its interaction with an N-terminal fragment of CX3CR1. Biochemistry 38, 1402-1414. doi: 10.1021/bi9820614

Mizumatsu, S., Monje, M. L., Morhardt, D. R., Rola, R., Palmer, T. D., and Fike, J. R. (2003). Extreme sensitivity of adult neurogenesis to low doses of X-irradiation. Cancer Res. 63, 4021-4027.

Monje, M. L., Mizumatsu, S., Fike, J. R., and Palmer, T. D. (2002). Irradiation induces neural precursor-cell dysfunction. Nat. Med. 8, 955-962. doi: 10.1038/nm749

Monje, M. L., Toda, H., and Palmer T. D. (2003). Inflammatory blockade restores adult hippocampal neurogenesis. Science 302, 1760-1765. doi: 10.1126/science.1088417

Mu, Y., and Gage, F. H. (2011). Adult hippocampal neurogenesis and it role in Alzheimer's disease. Mol. Neurodegener. 6, 85. doi: 10.1186/17501326-6-85

Nakashiba, T., Cushman, J. D., Pelkey, K. A., Renaudineau, S., Buhl, D L., Mchugh, T. J., etal. (2012). Young dentate granule cells mediate pattern separation, whereas old granule cells facilitate pattern completion. Cell 149, 188-201. doi: 10.1016/j.cell.2012.01.046

Nakatomi, H., Kuriu, T., Okabe, S., Yamamoto, S., Hatano, O., Kawahara, N., et al. (2002). Regeneration of hippocampal pyramidal neurons after ischemic brain injury by recruitment of endogenous neural progenitors. Cell 110, 429441. doi: 10.1016/S0092-8674(02) 00862-0
Neumann, J., Gunzer, M., Gutzeit, H. O., Ullrich, O., Reymann, K. G., and Dinkel, K. (2006). Microglia provide neuroprotection after ischemia. FASEB J. 20, 714-716. doi: 10.1096/fj.05-4882fje

Nimmerjahn, A., Kirchhoff, F., and Helmchen, F. (2005). Resting microglial cells are highly dynamic surveillants of brain parenchyma in vivo. Science 308, 1314-1318. doi: 10.1126/science.1110647

Paolicelli, R. C., Bolasco, G., Pagani, F., Maggi, L., Scianni, M., Panzanelli, P., etal. (2011). Synaptic pruning by microglia is necessary for normal brain development. Science 333 , 1456-1458. doi: 10.1126/science.1202529

Parent, J. M., Elliott, R. C., Pleasure, S. J., Barbaro, N. M., and Lowenstein, D. H. (2006). Aberrant seizure-induced neurogenesis in experimental temporal lobe epilepsy. Ann. Neurol. 59, 81-91. doi: 10.1002/ana.20699

Parent, J. M., Yu, T. W., Leibowitz, R. T., Geschwind, D. H., Sloviter, R. S., and Lowenstein, D. H. (1997). Dentate granule cell neurogenesis is increased by seizures and contributes to aberrant network reorganization in the adult rat hippocampus. J. Neurosci. 17, 3727-3738.

Piao, C. S., Stoica, B. A., Wu, J., Sabirzhanov, B., Zhao, Z., Cabatbat, R., etal. (2013). Late exercise reduces neuroinflammation and cognitive dysfunction after traumatic brain injury. Neurobiol. Dis. 54, 252 263. doi: 10.1016/j.nbd.2012.12.017

Porta, C., Rimoldi, M., Raes, G., Brys, L., Ghezzi, P., Di Liberto, D., et al. (2009). Tolerance and M2 (alternative) macrophage polarization are related processes orchestrated by $\mathrm{p} 50$ nuclear factor kappaB. Proc. Natl. Acad. Sci. U.S.A. 106, 14978-14983. doi: 10.1073/pnas.0809784106

Prinz, M., and Priller, J. (2010). Tickets to the brain: role of CCR2 and CX3CR1 in myeloid cell entry in the CNS. J. Neuroimmunol. 224, 80-84 doi: 10.1016/j.jneuroim.2010.05.015

Qin, L., Liu, Y., Hong, J. S., and Crews, F. T. (2013). NADPH oxidase and aging drive microglial activation, oxidative stress, and dopaminergic neurodegeneration following systemic LPS administration. Glia 61, 855-868. doi: 10.1002/glia.22479

Raber, J., Fan, Y., Matsumori, Y., Liu, Z., Weinstein, P. R., Fike, J. R., et al. (2004a). Irradiation attenuates neurogenesis and exacerbates ischemiainduced deficits. Ann. Neurol. 55, 381-389. doi: 10.1002/ana.10853

Raber, J., Rola, R., Lefevour, A., Morhardt, D., Curley, J., Mizumatsu, 
S., et al. (2004b). Radiation-induced cognitive impairments are associated with changes in indicators of hippocampal neurogenesis. Radiat. Res. 162, 39-47. doi: 10.1667/RR3206

Ramirez-Amaya, V., Marrone, D. F., Gage, F. H., Worley, P. F., and Barnes, C. A. (2006). Integration of new neurons into functional neural networks. J. Neurosci. 26, 12237-12241. doi: 10.1523/JNEUROSCI.2195-06. 2006

Rogers, J. T., Morganti, J. M., Bachstetter, A. D., Hudson, C. E., Peters, M. M., Grimmig, B. A., et al. (2011). CX3CR1 deficiency leads to impairment of hippocampal cognitive function and synaptic plasticity. J. Neurosci. 31, 16241-16250. doi: $\quad 10.1523 / J N E U R O S C I .3667-$ 11.2011

Rola, R., Fishman, K., Baure, J., Rosi, S., Lamborn, K. R., Obenaus, A., et al. (2008). Hippocampal neurogenesis and neuroinflammation after cranial irradiation with (56)Fe particles. Radiat. Res. 169, 626-632. doi: 10.1667/RR1263.1

Rosi, S. (2011). Neuroinflammation and the plasticity-related immediateearly gene Arc. Brain Behav. Immun. 25(Suppl. 1), S39-S49. doi: 10.1016/ j.bbi.2011.02.003

Rosi, S., Andres-Mach, M., Fishman, K. M., Levy, W., Ferguson, R. A., and Fike, J. R. (2008). Cranial irradiation alters the behaviorally induced immediate-early gene arc (activity-regulated cytoskeletonassociated protein). Cancer Res. 68, 9763-9770. doi: 10.1158/00085472.CAN-08-1861

Rosi, S., Belarbi, K., Ferguson, R. A., Fishman, K., Obenaus, A., Raber, J., et al. (2012). Traumainduced alterations in cognition and Arc expression are reduced by previous exposure to $56 \mathrm{Fe}$ irradiation. Hippocampus 22, 544-554. doi: 10.1002/hipo. 20920

Rosi, S., Ramirez-Amaya, V., Vazdarjanova, A., Worley, P. F., Barnes, C. A., and Wenk, G. L. (2005). Neuroinflammation alters the hippocampal pattern of behaviorally induced Arc expression. J. Neurosci. 25, 723 731. doi: 10.1523/JNEUROSCI.446904.2005

Sandoval, C. J., Martinez-Claros, M., Bello-Medina, P. C., Perez, O., and Ramirez-Amaya, V. (2011). When are new hippocampal neurons, born in the adult brain, integrated into the network that processes spatial information? PLoS ONE 6:e17689. doi: 10.1371/journal.pone.0017689
Sasaki, A., Kawarabayashi, T., Murakami, T., Matsubara, E., Ikeda, M., Hagiwara, H., et al. (2008). Microglial activation in brain lesions with tau deposits: comparison of human tauopathies and tau transgenic mice TgTauP301L. Brain Res. 1214, 159-168. doi: 10.1016/j.brainres.2008.02.084

Sasaki, A., Shoji, M., Harigaya, Y., Kawarabayashi, T., Ikeda, M., Naito, M., etal. (2002). Amyloid cored plaques in Tg2576 transgenic mice are characterized by giant plaques, slightly activated microglia, and the lack of paired helical filament-typed, dystrophic neurites. Virchows Arch. 441, 358-367. doi: 10.1007/s00428002-0643-8

Schilling, M., Besselmann, M., Muller, M., Strecker, J. K., Ringelstein, E. B., and Kiefer, R. (2005). Predominant phagocytic activity of resident microglia over hematogenous macrophages following transient focal cerebral ischemia: an investigation using green fluorescent protein transgenic bone marrow chimeric mice. Exp. Neurol. 196, 290-297. doi: 10.1016/j.expneurol.2005.08.004

Schmidt-Hieber, C., Jonas, P., and Bischofberger, J. (2004). Enhanced synaptic plasticity in newly generated granule cells of the adult hippocampus. Nature 429, 184-187. doi: 10.1038 /nature02553

Schwartz, M., and Shechter, R. (2010). Systemic inflammatory cells fight off neurodegenerative disease. Nat. Rev. Neurol. 6, 405-410. doi: 10.1038/nrneurol.2010.71

Seki, T., Namba, T., Mochizuki, H., and Onodera, M. (2007). Clustering, migration, and neurite formation of neural precursor cells in the adult rat hippocampus. J. Comp. Neurol. 502, 275-290. doi: 10.1002/cne.21301

Spalding, K. L., Bergmann, O., Alkass, K., Bernard, S., Salehpour, M., Huttner, H. B., et al. (2013). Dynamics of hippocampal neurogenesis in adult humans. Cell 153, 1219-1227. doi: 10.1016/j.cell.2013.05.002

Stalder, M., Phinney, A., Probst, A., Sommer, B., Staufenbiel, M., and Jucker, M. (1999). Association of microglia with amyloid plaques in brains of APP23 transgenic mice. Am. J. Pathol. 154, 1673-1684. doi: 10.1016/S0002-9440(10)65423-5

Sun, D., Mcginn, M. J., Zhou, Z., Harvey, H. B., Bullock, M. R., and Colello, R. J. (2007). Anatomical integration of newly generated dentate granule neurons following traumatic brain injury in adult rats and its association to cognitive recovery. Exp. Neurol. 204, 264-272. doi: 10.1016/j.expneurol.2006.11.005

Tada, E., Parent, J. M., Lowenstein, D. H., and Fike, J. R. (2000). Xirradiation causes a prolonged reduction in cell proliferation in the dentate gyrus of adult rats. Neuroscience 99, 33-41. doi: 10.1016/S03064522(00)00151-2

Thored, P., Heldmann, U., Gomes-Leal, W., Gisler, R., Darsalia, V., Taneera, J., et al. (2009). Long-term accumulation of microglia with proneurogenic phenotype concomitant with persistent neurogenesis in adult subventricular zone after stroke. Glia 57 , 835-849. doi: 10.1002/glia.20810

Toni, N., Laplagne, D. A., Zhao, C., Lombardi, G., Ribak, C. E., Gage, F. H., et al. (2008). Neurons born in the adult dentate gyrus form functional synapses with target cells. Nat. Neurosci. 11, 901-907. doi: 10.1038/nn.2156

Tran, P. B., Banisadr, G., Ren, D., Chenn, A., and Miller, R. J. (2007). Chemokine receptor expression by neural progenitor cells in neurogenic regions of mouse brain. J. Comp. Neurol. 500, 1007-1033. doi: 10.1002/cne.21229

Tremblay, M. E., Lowery, R. L., and Majewska, A. K. (2010). Microglial interactions with synapses are modulated by visual experience. PLoS Biol. 8:e1000527. doi: 10.1371/journal.pbio. 1000527

Trouche, S., Bontempi, B., Roullet, P., and Rampon, C. (2009). Recruitment of adult-generated neurons into functional hippocampal networks contributes to updating and strengthening of spatial memory. Proc. Natl. Acad. Sci. U.S.A. 106, 5919-5924. doi: 10.1073/pnas.0811054106

Turrin, N. P., and Rivest, S. (2004). Innate immune reaction in response to seizures: implications for the neuropathology associated with epilepsy. Neurobiol. Dis. 16, 321-334. doi: 10.1016/j.nbd.2004.03.010

Vallieres, L., Campbell, I. L., Gage, F. H., and Sawchenko, P. E. (2002). Reduced hippocampal neurogenesis in adult transgenic mice with chronic astrocytic production of interleukin-6. J. Neurosci. 22, 486-492.

Vezzani, A., Ravizza, T., Balosso, S., and Aronica, E. (2008). Glia as a source of cytokines: implications for neuronal excitability and survival. Epilepsia 49(Suppl. 2), 24-32. doi: 10.1111/j.1528-1167.2008.01490.x

Wake, H., Moorhouse, A. J., Jinno, S., Kohsaka, S., and Nabekura, J.
(2009). Resting microglia directly monitor the functional state of synapses in vivo and determine the fate of ischemic terminals. J. Neurosci. 29, 3974-3980. doi: 10.1523/JNEUROSCI.4363-08.2009

Wu, M. D., Hein, A. M., Moravan, M. J., Shaftel, S. S., Olschowka, J. A., and O'Banion, M. K. (2012). Adult murine hippocampal neurogenesis is inhibited by sustained IL-1beta and not rescued by voluntary running. Brain Behav. Immun. 26, 292-300. doi: 10.1016/j.bbi.2011.09.012

Yagita, Y., Kitagawa, K., Ohtsuki, T., Takasawa, K., Miyata, T., Okano, H., et al. (2001). Neurogenesis by progenitor cells in the ischemic adult rat hippocampus. Stroke 32, 1890-1896. doi: 10.1161/01.STR.32. 8.1890

Yi, M. H., Zhang, E., Kang, J. W., Shin, Y. N., Byun, J. Y., Oh, S. H., et al. (2012). Expression of CD200 in alternative activation of microglia following an excitotoxic lesion in the mouse hippocampus. Brain Res. 1481, 90-96. doi: 10.1016/j.brainres.2012. 08.053

Yoshiyama, Y., Higuchi, M., Zhang, B., Huang, S. M., Iwata, N., Saido, T. C., etal. (2007). Synapse loss and microglial activation precede tangles in a P301S tauopathy mouse model. Neuron 53, 337-351. doi: 10.1016/j.neuron.2007.01.010

Conflict of Interest Statement: The authors declare that the research was conducted in the absence of any commercial or financial relationships that could be construed as a potential conflict of interest.

Received: 29 April 2013; accepted: 21 August 2013; published online: 06 September 2013.

Citation: Belarbi K and Rosi S (2013) Modulation of adult-born neurons in the inflamed hippocampus. Front. Cell. Neurosci. 7:145. doi: 10.3389/fncel.2013. 00145

This article was submitted to the journal Frontiers in Cellular Neuroscience. Copyright (C) 2013 Belarbi and Rosi. This is an open-access article distributed under the terms of the Creative Commons Attribution License (CC BY). The use, distribution or reproduction in other forums is permitted, provided the original author(s) or licensor are credited and that the original publication in this journal is cited, in accordance with accepted academic practice. No use, distribution or reproduction is permitted which does not comply with these terms. 